Clío América/ Vol. 14, No. 27 - 2020 / 454 - 468

http://dx.doi.org/10.21676/23897848.3759

\title{
Marketing viral: Aplicación y tendencias
}

The Viral marketing: Application and trends

\section{Pedro Duque-Hurtado ${ }^{1}$, Adrián Toro-Cardona ${ }^{2}$ (D), Dahiana Ramírez-Ramírez ${ }^{3}$ y Martin Carvajal-Henao $^{4}$ (D)}

${ }^{1}$ Universidad Católica Luis Amigó, Colombia.Email: pedro.duquehu@amigo.edu.co

${ }^{2}$ Universidad Católica Luis Amigó, Colombia. Email: adrian.toroca@ amigo.edu.co

${ }^{3}$ Universidad Católica Luis Amigó, Colombia. Email: dahiana.ramirezca@amigo.edu.co

${ }^{4}$ Universidad Católica Luis Amigó, Colombia. Email: martin.carvajalhe@ amigo.edu.co

Para citar este artículo: Duque, P., Toro, C. A., Ramírez, C. D. y Carvajal, H. M. (2020). Marketing viral: el uso de las redes sociales. Clío América, 14(27), 454-468. http://dx.doi.org/10.21676/23897848.3759

Recibido: 5 diciembre de 2019

Aceptado: 26 de febrero de 2020

Publicado en línea: marzo 03 de 2020

\section{Palabras clave: marketing viral; redes sociales; boca o boca; marketing digital; bibliometría.}

JEL: M31.

\section{RESUMEN}

El propósito de este documento es explorar la estructura intelectual del marketing viral, su evolución y tendencias de investigación. Para ello, a partir de técnicas y herramientas de la cienciometría, se efectuó un análisis de citaciones a partir de 188 publicaciones realizadas sobre el tema, desde el año 2000 hasta el 2020, en la base de datos Web of Science. Este artículo identifica tres subáreas que han emergido de la literatura: la primera, se enfoca en los factores que generan influencia en la toma de decisiones de los consumidores cuando se interactúa con el contenido generado por la empresa; la segunda, explora cómo el marketing viral se ha visto potenciado a partir de la llegada de las redes sociales; la tercera, finalmente, estudia el uso de influenciadores como elemento dinamizador de las campañas de este tipo. Este trabajo explora la intersección entre la disciplina de marketing y el uso de las redes sociales; en especial, cómo estas últimas son un elemento para la propagación de los mensajes de las compañías y de los consumidores.

\section{ABSTRACT}

The purpose of this document is to explore the intellectual structure of viral marketing, its evolution and research trends. To this end, using scientometric techniques and tools, an analysis of citations was made, based on 188 publications on the subject, from 2000 to 2020, in the Web of Science database. This article identifies three sub-areas that have emerged from the literature. The first one focused on the factors that generate influence in the consumers' decision making, when interacting with the content generated by the company; the second, explores how viral marketing has been enhanced by the advent of social networks; finally, the third one studies the use of influencers as a dynamic element in campaigns of this type. This work explores the intersection between the discipline of marketing and the use of social networks, especially as the latter are an element for the propagation of the messages of companies and consumers.

Keywords:

viral

marketing;

social media;

word of

mouth

(wom);

digital

marketing;

bibliometric. 


\section{INTRODUCCIÓN}

El marketing viral (MV) es señalado por Akpinar y Berger (2017) como el "Santo Grial" del marketing digital; esto se debe a que las campañas de MV se pueden implementar a través de programas y herramientas de comunicación potentes, pero asequibles (Satrio et al., 2020). Por este motivo, es la herramienta preferida de las empresas para abarcar una mayor población y generar recordación y posicionamiento en los mercados. La revisión literaria da luces sobre lo anterior. Dobele et al. (2007) sugieren que las campañas de MV son más exitosas cuando desatan una respuesta emocional en los receptores. Así mismo, al tener un alto número de dispositivos móviles en el mercado se favorece el uso del marketing móvil. Sin embargo, Pescher et al. (2014) indican que el éxito de las mismas está sujeto a la voluntad de los consumidores de replicar o reenviar de manera activa estos anuncios a sus conocidos.

Sin embargo, a pesar de la relevancia del tema, aún no se ha realizado una revisión que muestre su evolución y que identifique, además, las corrientes de investigación que emergen sobre el MV. Se identifica una sola revisión que se aproxima al tema. Reichstein y Brusch (2019) efectuaron un estudio de la literatura sobre el tema, pero enfocado al campo de la toma de decisiones, identificando dos etapas: la primera, cuando el consumidor acepta el contenido, y la segunda, cuando decide interactuar con él. No obstante, esa fue su limitación principal: el enfoque en la toma de decisiones. Cabe anotar que solo se halló este artículo de revisión, donde se analizan los hallazgos más importantes de los últimos 20 años en el tema, pero se deja la puerta abierta a futuras investigaciones. Por lo anterior, el propósito de este artículo es llenar el vacío identificado en la literatura, presentando de una manera cronológica los diferentes aportes, la evolución y las subáreas del MV a través del tiempo.

Con el fin de atender este propósito, inicialmente se efectuó la consulta en la base de datos Web of Science (WoS) sobre marketing viral. Después, se procesaron los registros empleando la metáfora del árbol. Luego, se obtuvieron los principales trabajos de acuerdo a la posición en el árbol: en la raíz, las investigaciones clásicas; en el tronco, las estructurales; en las hojas, las investigaciones actuales. Esta forma de presentar la estructura de conocimiento del área permite explorar su evolución y, además, facilita la identificación de sus tendencias de investigación.

El documento se articula en tres apartados adicionales a la introducción: el primero, describe la metodología empleada para llevar a cabo la investigación; el segundo, expone los resultados obtenidos, y, finalmente, el tercero relaciona las conclusiones y limitaciones del estudio.

\section{METODOLOGÍA}

La metodología se realizó en tres pasos. Inicialmente, un análisis a través de indicadores cienciométricos, validando la relevancia del tema mediante el uso de la herramienta Bibliometrix (Aria y Cuccurullo, 2017), la cual facilita el mapeo científico del tema. Seguido a esto, se analizó cronológicamente, haciendo uso de la representación del árbol. Por último, se muestran las tres tendencias de investigación del tema; para ello, se empleó el análisis de cocitaciones y la herramienta Gephi (Mathieu et al., 2009).

\section{Paso 1: análisis cienciométrico}

Para elaborar este documento se usaron herramientas para conocer la forma en la que ha evolucionado el MV y para identificar, además, sus diferentes subáreas o perspectivas de investigación. A partir de una consulta en la base de datos WoS, se identificaron los trabajos que hablan del marketing viral; esto, usando la ecuación de búsqueda: "título: (marketing) y tema: (viral)", con un rango de fecha de enero de 2000 a diciembre 31 de 2019 y obteniendo un resultado de 188 registros sobre el tema.

\section{Paso 2: árbol}

Los resultados obtenidos en la consulta se procesaron empleando la metáfora del árbol (Robledo et al., 2014, Hernández et al., 2020), la cual brinda la posibilidad de construir y entender de forma práctica el estado del arte, partiendo de la consulta en WoS. Este algoritmo está basado en la teoría de grafos, representando las investigaciones como nodos y las citaciones mediante links. Es así como una unidad de conocimiento es representada con un nodo ubicado en la red. Se clasifican los más importantes de acuerdo a su posición, determinada a su vez de acuerdo al número de links que los conectan. Por ello, los más citados se encuentran en la raíz, en el tronco se encuentran los trabajos citados por las hojas y que citan a su vez a la raíz. Finalmente, en las hojas se encuentran las investigaciones que citan a los otros dos segmentos del árbol: es así como se da forma al árbol de la ciencia.

Después de contar con la estructura del árbol, se analizan los trabajos más importantes en cada categoría. De esta manera, se obtiene un panorama de las bases fundamentales del tema, además de identificar los desarrollos actuales sobre el MV. 


\section{Paso 3: análisis de citaciones}

Las diferentes subáreas encontradas para el marketing viral parten de un análisis de cocitaciones, aplicando un algoritmo especializado de clusterización (Blondel et al., 2008). Se analizan las subáreas a través de la minería de texto con la herramienta Bibliometrix, mediante el algoritmo Wordcloud (Ohri, 2012). Finalmente, se utiliza Gephi para visualizar la red de cocitaciones, donde cada investigación se representa con un nodo y cada enlace como una especie de arista. Para refinar la red se aplican filtros de componente gigante; con esto, se encuentran los nodos que se conectan entre sí y se eliminan los nodos desconectados (Freeman, 1977).

Esta metodología ha sido usada por otras investigaciones, generando valiosos resultados (Duque, Samboni, et al., 2020; Zuluaga et al., 2016; Duque y Cervantes, 2019; Buitrago et al., 2020; Duque y Duque, 2020; Salazar et al., 2020; Duque et al., 2021).

\section{RESULTADOS}

\section{Relevancia del tema}

La Figura 1 relaciona la publicación de trabajos científicos en la base de datos WoS sobre el tema MV para el periodo comprendido entre los años 2001 y 2019: un total de 185 registros. Hasta el 2010 se publicaron 32 documentos; de este año en adelante la producción acerca del tema ha aumentado considerablemente. Durante el 2015, año en el cual se realizó la mayor producción científica sobre el tema, se alcanzaron 24 artículos, que representan el $13 \%$ del total de publicaciones. De igual manera, en el periodo comprendido entre el 2011 y el 2019 se produjeron el $77 \%$ de las investigaciones sobre MV, demostrando el aumento de interés de la comunidad científica sobre el tema tratado, lo que nos refleja una tasa de incremento anual de un 26,91 $\%$ en WoS.

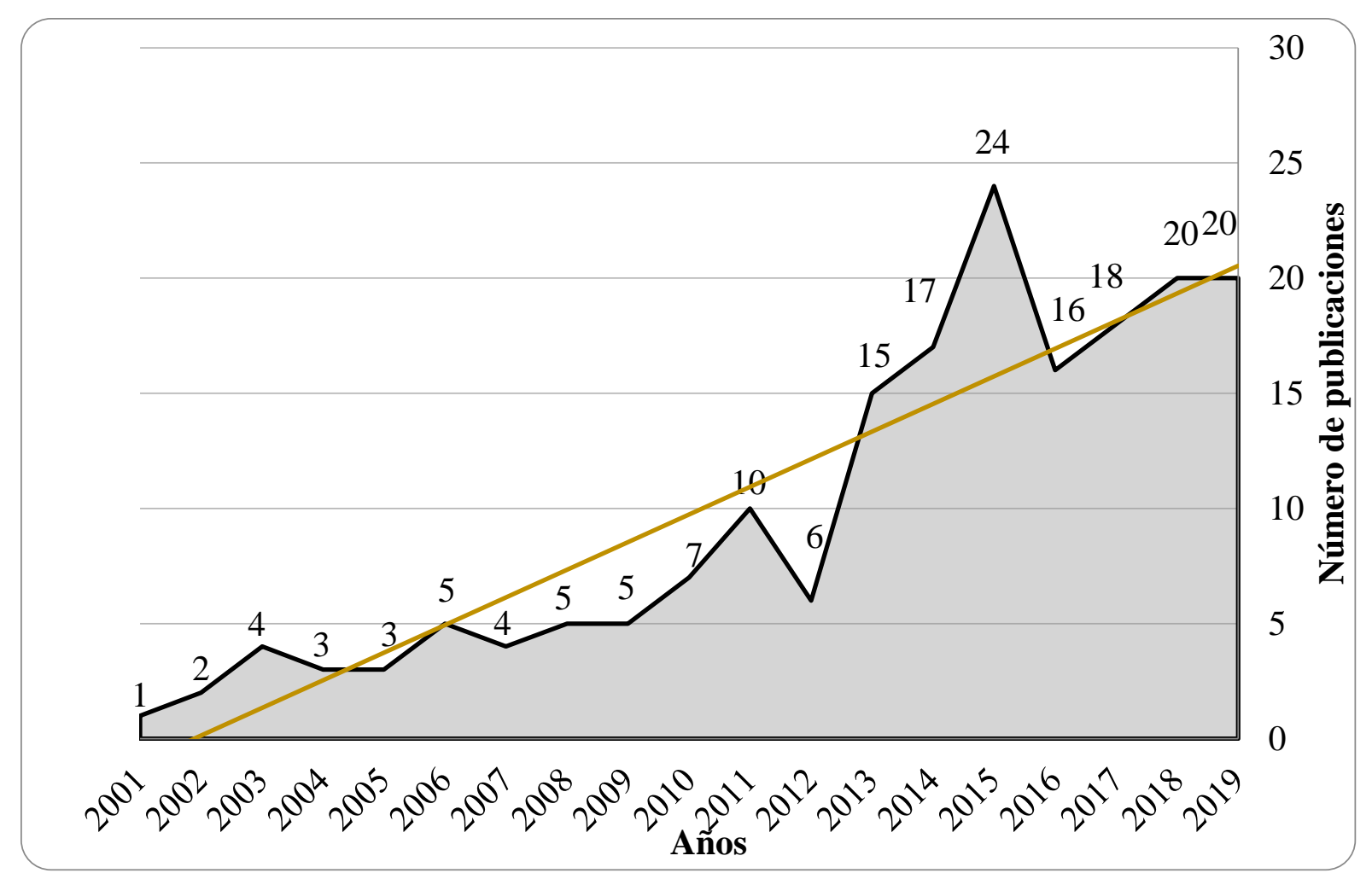

Figura 1. Producción científica anual en Marketing Viral Fuente: elaboración propia

En la Tabla 1 se muestran las cinco revistas científicas en las que se han publicado más investigaciones vinculadas al tema de MV en la base de datos WoS; además, se muestra el cuartil. Tres de ellas se encuentran en Q2, una en Q3 y otra no registra cuartil, lo que muestra la importancia de las mismas y soporta los conceptos relacionados en este artículo. 
Pedro Duque-Hurtado, Adrián Toro-Cardona, Dahiana Ramírez-Carvajal y Martin Eugenio Carvajal-Henao

Tabla 1. Revistas científicas más importantes

\begin{tabular}{|l|c|c|}
\hline \multicolumn{1}{|c|}{ Revista } & Artículos & Cuartil \\
\hline Plos One & 5 & Q2 \\
\hline Marketing and Management of Innovations & 4 & - \\
\hline $\begin{array}{l}\text { Physica A: Statistical Mechanics and its } \\
\text { Applications }\end{array}$ & 4 & Q2 \\
\hline Virology & 4 & Q3 \\
\hline Food and Environmental Virology & 3 & Q2 \\
\hline
\end{tabular}

Fuente: elaboración propia

\section{Mirada histórica - Tree of science}

Los artículos que se ubican en la raíz del "árbol de la ciencia" hacen referencia al enfoque del marketing viral. Dobele et al. (2007) plantean que los mensajes virales cuentan con seis emociones (sorpresa, alegría, tristeza, enojo, miedo y asco), pero para ser exitosos deben contar con un elemento sorpresa. Sin embargo, no basta con eso: deben tenerse en cuenta otros factores como el género al cual se dirigen, las emociones que quieren activar y el medio usado. De esta manera, se identifica que el uso de los dispositivos móviles es cada vez más notable para este fin, debido a que es una necesidad de comunicación de las nuevas generaciones y vinculante con las anteriores. Por lo anterior, se hace visible la posibilidad de maximización en la propagación de la influencia del mensaje mediante las redes sociales y los dispositivos móviles. Chen et al. (2010) comentan que el factor clave para que el MV prevalezca utilizando las redes sociales es la escalabilidad de la maximización de la influencia. Así mismo, Dobele et al. (2005) mencionan que las campañas de MV exitosas están compuestas de un mensaje atractivo que: contiene imaginación, diversión e intriga; fomenta la facilidad de uso y visibilidad; apunta a fuentes creíbles, y aprovecha las combinaciones de tecnología. Al hilo de lo anterior, se han estudiado modelos para que las ideas e influencias se propaguen por las redes sociales, sobre todo en las innovaciones médicas y tecnológicas; esto, con el objetivo de desencadenar nuevas adopciones en forma de cascada, surgiendo como principal una cuestión: ¿a qué conjunto de individuos se debería apuntar? (Kempe et al., 2003). Van der lans et al. (2010) reafirman este concepto: indican que una organización crea un mensaje y motiva a los clientes a propagarlo entre sus contactos, generando con ello una reacción en cascada. No obstante, no existen modelos de predicción para saber a cuántos clientes puede alcanzar una campaña de MV ni cómo podrían influir los especialistas en este proceso usando actividades propias del marketing.
Los documentos que dan estructura al tema se ubican en el tronco. Es así como Pescher et al. (2014) sugieren que es conveniente identificar los factores que influyen en el comportamiento y concluyen tres etapas del comportamiento de referencia: importancia, interés y derivación. El caso de FarmVille es prueba de lo anterior. Schulze et al. (2014) realizan un estudio empírico analizando las campañas de 751 productos e identificando el mismo mecanismo que usó FarmVille para compartir; sin embargo, no es de gran ayuda para promover productos utilitarios. Como consecuencia, se puede evidenciar que, siendo los móviles y las redes sociales importantes como medios de difusión de mensajes de marketing, se deben identificar posibles riesgos y tratar de minimizarlos. Aunque el marketing viral atrae la atención en la prensa comercial, se conoce poco sobre las motivaciones y los comportamientos de las personas, quienes son el componente esencial de esta estrategia (Phelps et al., 2004). Pese a esto, cabe resaltar que el crecimiento exponencial de internet y las referencias electrónicas entre pares se han convertido en un fenómeno importante (De Bruyn y Lilien, 2008), haciendo de este medio uno de los preferidos por los especialistas en marketing, quienes han tratado de explotarlo. El MV es la forma de comunicación que motiva a las personas a transmitir un mensaje mediante sus redes sociales; no obstante, la sabiduría convencional muestra que este es aleatorio e inmanejable (Bampo et al., 2008).

En las hojas se ubican las subáreas de investigación identificadas. Entre estos documentos se encuentran Blichfeldt y Smed (2015), quienes aseguran que los especialistas de marketing buscan cada vez más que sus mensajes lleguen a los usuarios de redes sociales, quienes a su vez comparten con sus contactos, semejando esta difusión a un virus, sin medir el impacto. Sin embargo, 
Reichstein y Brusch (2019) muestran que el MV se utiliza para distribuir contenido y en este estudio se realiza un análisis en el proceso de toma de decisiones de los individuos, dividiéndolo en dos etapas. La primera, donde se decide si se considera revisar el contenido, y la segunda, donde se decide si se interactúa con el mismo. También Almeida et al. (2016) proponen en su estudio el análisis de diferentes contenidos en una de las más populares redes sociales (Facebook), donde determinaron que existe una relación positiva entre las categorías marcadas como publicidad y marketing digital después de analizar 2583 publicaciones en ocho perfiles de marcas de cerveza brasileñas. De igual manera, se evidencia que no solo las redes sociales son usadas para estas campañas; también el correo electrónico. En un estudio de naturaleza descriptiva, Sharma y Kaur (2020) revelan cómo la intención de abrir los correos está influenciada por el valor percibido del contenido y la relación con el remitente. Por último, Sela et al. (2018) definen los grupos de usuarios de redes sociales como nodos, donde el vendedor activa en inicio un nodo pequeño y, seguido a esto, se empieza el proceso de viralización pasivo, donde sin influencia externa este nodo va infectando a los demás. Sin embargo, no hay adición de productos como consecuencia de esta viralización; por ello, en este estudio se propone un nuevo modelo para esa viralización, al que llaman Active MV, donde la adopción de productos depende de qué tan continuo se hace promoción activa por parte del vendedor. De esta manera, el marketing viral está presente cada vez más en las campañas publicitarias de las empresas, con el fin de generar influencia en las decisiones que toman las personas a las que llegan, y su objetivo es difundir el mensaje a manera de virus (Blichfeldt y Smed, 2015). Los documentos analizados pueden identificarse en la Figura 2.

Figura 2. Árbol de la ciencia del marketing viral

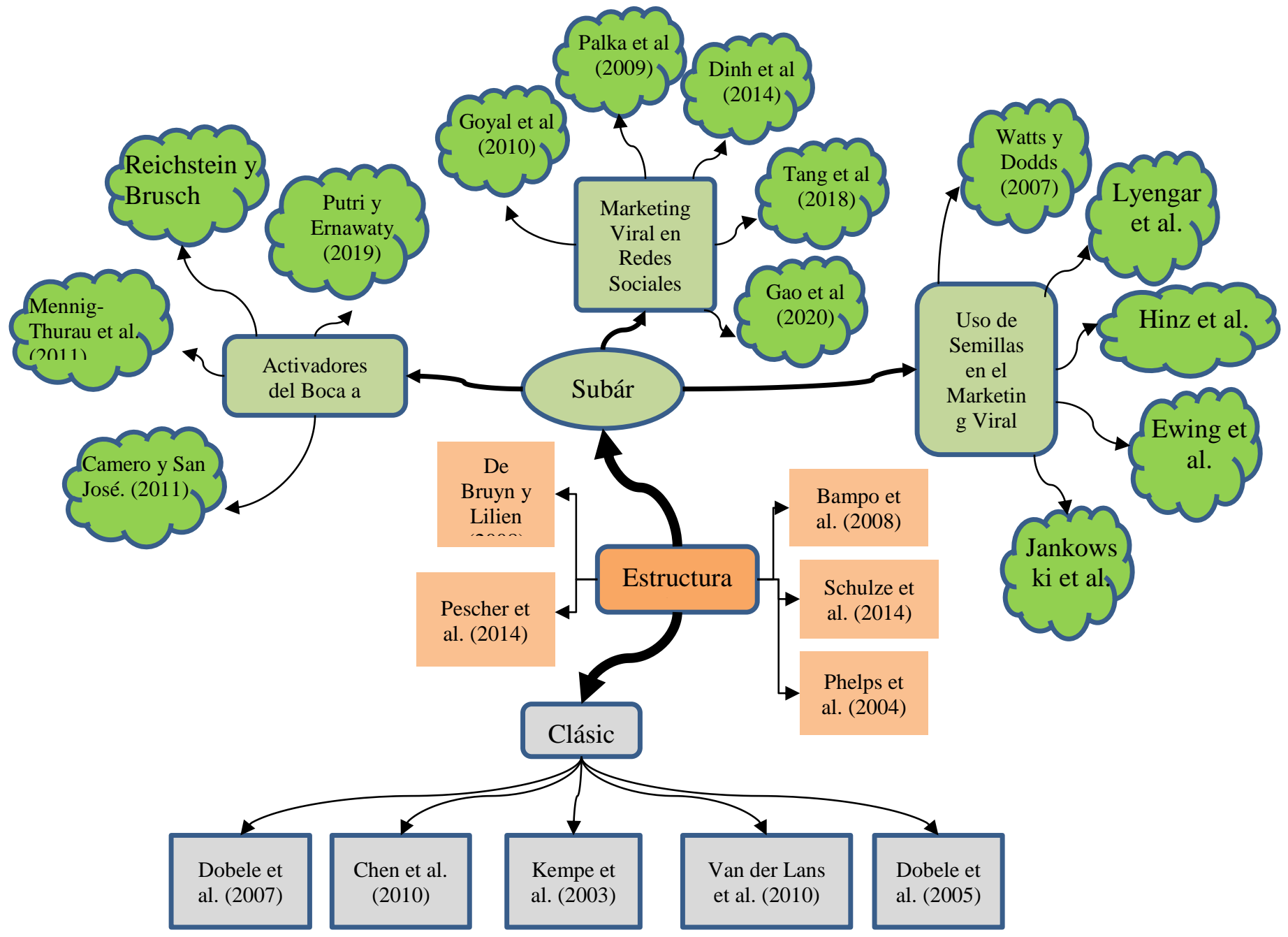

Fuente: elaboración propia 
Subáreas que emergen de la literatura

La red de citaciones se detalla en la Figura 3, donde se identifican tres enfoques o grupos en el MV. La red tiene 253 documentos (artículos). Se visualizan dentro de la red diferentes clúster (Blondel et al., 2008), identificando tres subáreas. Los artículos con más citaciones se representan con un nodo más grande: esto indica que son clasificados como los más influyentes en el campo estudiado.

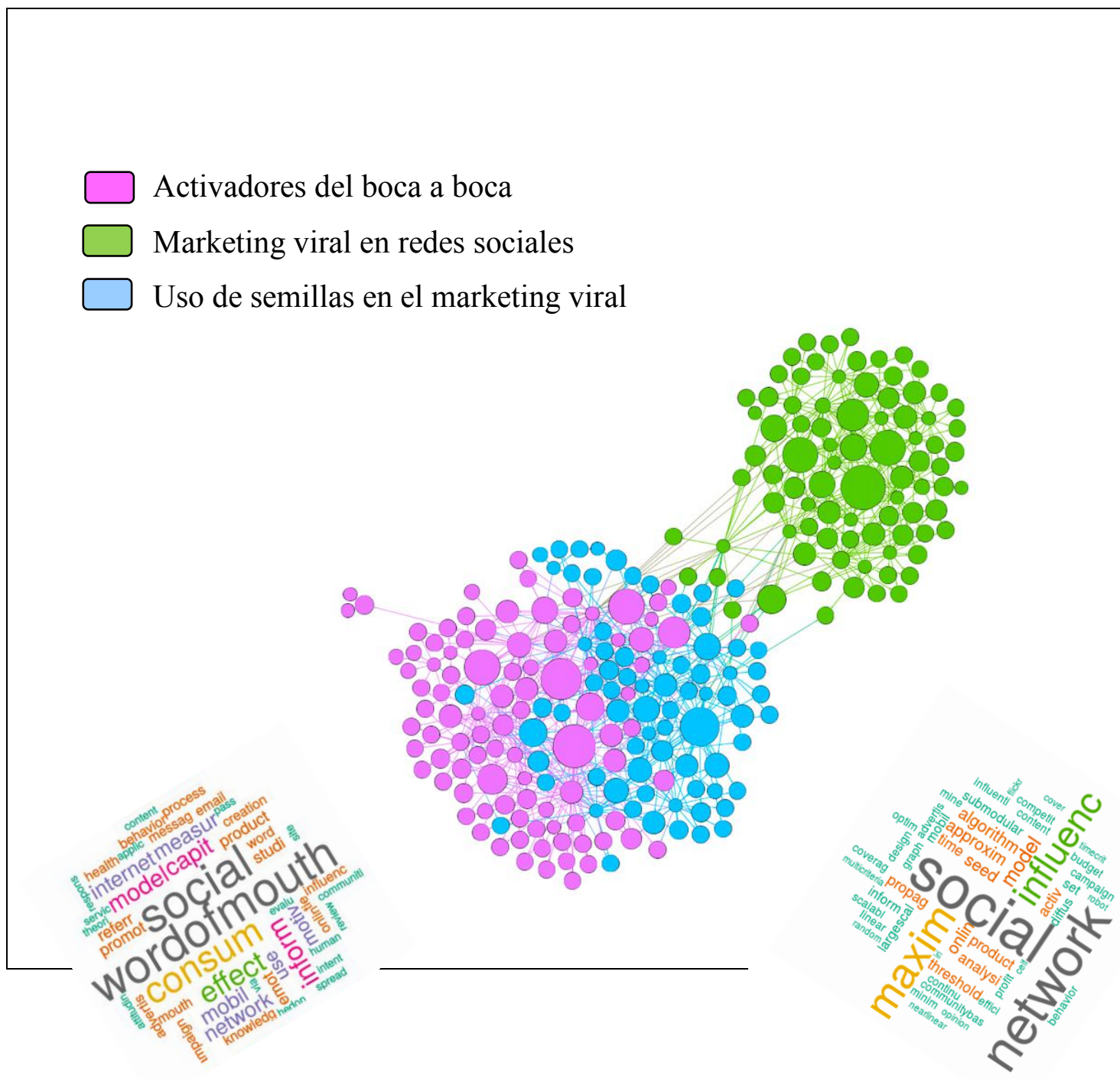

Figura 3. Red de Citaciones del Marketing Viral.

Fuente: elaboración propia.

\section{Subárea 1. Activadores del Boca a Boca}

Se identifican los factores que influencian el comportamiento de referencia en MV utilizando tanto el "boca a boca" (WOM) como el "boca a boca por internet" (eWOM). Al identificar los artículos en esta subárea, se comienza por aquellos que dan base al tema. Por ejemplo, Hennig-Thurau et al. (2004) refieren la participación en la comunicación electrónica del boca a boca; como resultado, muestran cuatro motivantes que conducen al comportamiento de eWOM: la interacción social, el deseo de incentivos económicos, su preocupación por otros consumidores y el potencial para mejorar la autoestima. De igual manera, Palka et al. (2009) realizan una investigación con el fin de validar los motivantes para la interacción con las campañas de MV móvil, buscando factores determinantes para el uso, la recepción y el posterior reenvío del contenido viral. Así mismo, Brown y Reingen (1987) analizan la referencia de boca a boca como lazos sociales débiles y fuertes, a niveles micro y macro, encontrando que a nivel micro son más influyentes los lazos fuertes para ser utilizados como fuente de información, caso contrario a nivel macro, donde cobran 
gran importancia los lazos débiles. Por último, Herr et al. (1991), en su investigación acerca de los efectos de las comunicaciones WOM y la información de atributos específicos en las evaluaciones de productos, muestran que diversos fenómenos de juicio aparentemente no relacionados como el efecto de viveza, el efecto de perseverancia y el efecto de negatividad pueden explicarse a través del modelo de diagnóstico de accesibilidad.

A través de los años, los investigadores demuestran que el intercambio informal de información entre personas conocidas influye tanto en las elecciones como en las decisiones que toman los consumidores finales al comprar (De Bruyn y Lilien, 2008). Pescher et al. (2014) determinan, en el MV, las referencias entre positivas y negativas, donde la reducción de la ansiedad, la búsqueda de consejo y la venganza son algunos de los factores que generan referencias negativas. El MV cada vez crece más como estrategia de comunicación por su bajo costo y por los resultados que se obtienen. Sin embargo, para que sea exitosa dependerá de varios factores; entre ellos, el llamado "dinámica viral" del individuo (Camarero y San José, 2011), que hace referencia al proceso de enviar y recibir mensajes entre personas en su red de contactos.

Finalmente, se muestran los artículos que exponen los resultados más recientes. Reichstein y Brusch (2019) identifican tres niveles de decisión en su investigación sobre el proceso en la toma de decisiones en el MV: recepción/conciencia, interés/apertura y reenvío (y los diferentes factores que influyen en estos). Hoy en día, como se mencionaba anteriormente, el MV es muy popular como estrategia de marketing altamente efectiva y de bajo costo para la focalización masiva (Putri y Ernawaty, 2019). Sin embargo, con todo y lo que se ha investigado sobre el tema, se conoce muy poco sobre el efecto de las tácticas promocionales tradicionales en las decisiones de referencia del consumidor. En un experimento de campo aleatorio sobre un servicio de moda en línea llamado Style Crowd, realizado por Koch y Benlian (2015), se investigaron los efectos de la escasez y la personalización, dos señales promocionales clásicas que se han vuelto omnipresentes en la web y hasta ahora han recibido una atención mínima sobre el comportamiento real de referencia.

\section{Subárea 2. Marketing Viral en Redes sociales}

Esta subárea se enfoca en el uso de redes sociales en el MV. Kempe et al. (2003) hacen referencia al tema en las relaciones e interacciones de las personas, poniendo como ejemplo el uso del celular entre estudiantes universitarios, lo que juega un papel esencial en la difusión del mensaje, en las nuevas ideas y en la generación de influencia entre los miembros de la red. Goya et al. (2010) desarrollan técnicas para predecir el tiempo en el que se espera que un usuario realice una acción para propagar el mensaje en su red social. Palka et al. (2009) intentan comprender las motivaciones que tiene el consumidor para participar en estrategias de MV en los móviles, ayudando a los investigadores y especialistas en marketing a comprender mejor los componentes críticos de las estrategias de MV.

Las redes sociales en línea son, hoy en día, uno de los canales con mayor eficacia para los campos de marketing y publicidad, ya que se utilizan para aumentar la adopción de productos o difundir ampliamente el contenido en la red (Dinh et al., 2014). Long y Wong (2014) muestran, en su estudio, que las empresas suponen que todos los usuarios de la red social son potenciales consumidores de sus productos. Sin embargo, puede no ser cierto en todos los casos; debido a esto, proponen un paradigma nuevo de MV: en él, la empresa define los tipos de clientes en la red social que son de interés al promocionar los productos. Aslay et al. (2015) estudian la problemática de asignar anuncios a través de las lentes del marketing viral, mostrando que si dicha asignación tiene en cuenta la propensión de los anuncios a la propagación viral puede llegar a lograr un rendimiento mucho mejor.

El marketing viral es una herramienta muy usada en la que los usuarios semilla anuncian nuevos productos 0 actividades comerciales. Tang et al. (2018) muestran que la selección de los usuarios iniciales (semilla) representa una compensación entre el gasto y los ingresos derivados del MV y realizan un estudio exhaustivo buscando un conjunto de nodos semilla que maximicen dicho beneficio. La influencia y la adopción del producto pueden extenderse de pocos influyentes semilla o clave a miles de millones de usuarios en la red; de ahí la importancia de identificar al influyente clave con el fin de maximizar la influencia (Nguyen et al., 2017). Gao et al. (2020) argumentan que la difusión de la influencia se ha estudiado de una manera amplia; sin embargo, la literatura existente está basada en el producto usado por una sola persona. Por ello, su estudio se enfoca en un producto que usan muchas personas, como los juegos en línea: estos generan interacción entre muchas personas y están acompañados de anuncios (por los que los operadores pueden recibir ingresos). Al tratarse de un producto usado por múltiples consumidores, aumenta la viralidad del mensaje. Por su parte, Huang et al. (2019) proponen en su investigación un nuevo modelo de maximización de la influencia basados en la ubicación de la influencia de una comunidad antes que en la detección de la comunidad de manera independiente.

\section{Subárea 3. Uso de semillas en el marketing Viral}

Esta última subárea ayuda a identificar cómo las campañas 
de marketing viral usan clientes o personas bien conectadas para que hagan difusión; a ellas se les denomina normalmente como semillas. Watts y Dodds (2007) desarrollan una idea a la que llaman "Hipótesis de los influyentes", donde una minoría de personas influye en un número excepcional de sus pares, convirtiéndose en parte fundamental e incidiendo en la opinión pública. De igual manera, se debe reconocer que la difusión del boca a boca y la consecución de ventas futuras dependerá de ventas pasadas (Godes y Mayzlin, 2004). Iyengar et al. (2011) realizan una investigación sobre cómo el liderazgo de opinión y el contagio social dentro de las redes sociales influyen en la compra de nuevos productos. Uno de sus hallazgos clave es que las medidas de liderazgo sociométricas y autoinformadas están correlacionadas y posiblemente asociadas con diferentes tipos de comportamientos relacionado con la adopción de nuevos productos, lo que sugiere que probablemente capturen diferentes construcciones.

El éxito del MV se ve fuertemente influenciado por las estrategias de siembra. Por ello, Hinz et al. (2011) comparan cuatro estrategias de siembra. Como resultado, muestran que sembrar en personas bien conectadas es el enfoque más exitoso porque estos puntos de siembra atractivos presentan alta probabilidad de participar en campañas de marketing viral. Es importante resaltar que el MV no es un concepto nuevo; sin embargo, el aumento del uso de redes sociales lleva el concepto a otro nivel. En 1996, el proveedor de correo electrónico Hotmail comenzó una de las primeras campañas de MV al adjuntar un mensaje promocional a cada correo electrónico enviado a través de su servicio (Schulze et al., 2014). Hoy en día, el MV es usado como herramienta convencional para las campañas de marketing. Kaplan y Haenlein (2011) consideran tres condiciones necesarias para crear una epidemia de marketing viral: dar el mensaje adecuado a los mensajeros adecuados en el ámbito correcto; con ello, presentan cuatro diferentes campañas de MV en redes sociales (pesadillas, golpes de suerte, problemas caseros y triunfos). Un ejemplo de influenciadores o personas semilla que usan las redes sociales para mantener vigencia es Britney Spears: ella y su equipo de empleados confían en las aplicaciones de redes sociales para comunicarse en torno a este ícono pop y crear y mantener su imagen de marca de celebridad (Kaplan y Haenlein, 2012).

Las campañas de marketing que utilizan la estrategia de siembra (SMC) alientan a difundir el boca a boca. Chae et al. (2017) investigan los efectos indirectos relacionados con SMC y los estiman de manera empírica con datos que cubren 390 SMC para productos de 192 marcas de cosméticos diferentes, encontrando efectos de desbordamiento en el boca a boca a nivel de marca y categoría; es decir, aumenta el boca a boca del producto focal, pero lo aleja de otros productos (incluso de la misma marca). Ewing et al. (2014) aportan al tema del MV dos componentes importantes en las campañas, aduciendo que las mismas no son puramente virales, sino que tienen componente viral (trasmisión entre iguales) y no viral (transmisión iniciada por la empresa). Sin embargo, comentan que las métricas con las que se evalúan las campañas pocas veces diferencian dichos componentes. Finalmente, Jankowski et al. (2017) examinan la efectividad del marketing viral y una campaña de apoyo, con el fin de evaluar si la campaña de apoyo evita el desbordamiento y permite mejorar la efectividad de campañas virales de menor rendimiento; como resultado, mencionan que los mundos virtuales pueden proporcionar un entorno parecido a un laboratorio para identificar los procesos que sustentan el marketing viral.

En la Figura 4 se presenta un resumen de las subáreas. Se propone, según lo visto en esta primera subárea, un modelo del flujo del mensaje del boca a boca, donde intervienen sus motivadores, el nivel de decisión y el impacto que genera, y donde se especifica a qué nivel se impacta si se genera con lazos fuertes o débiles; además, se muestra cómo las empresas usan personas con una red social amplia como semilla para entregar el mensaje y poder viralizar su campaña de marketing a una escala mayor. 
Figura 4. Resumen Subáreas

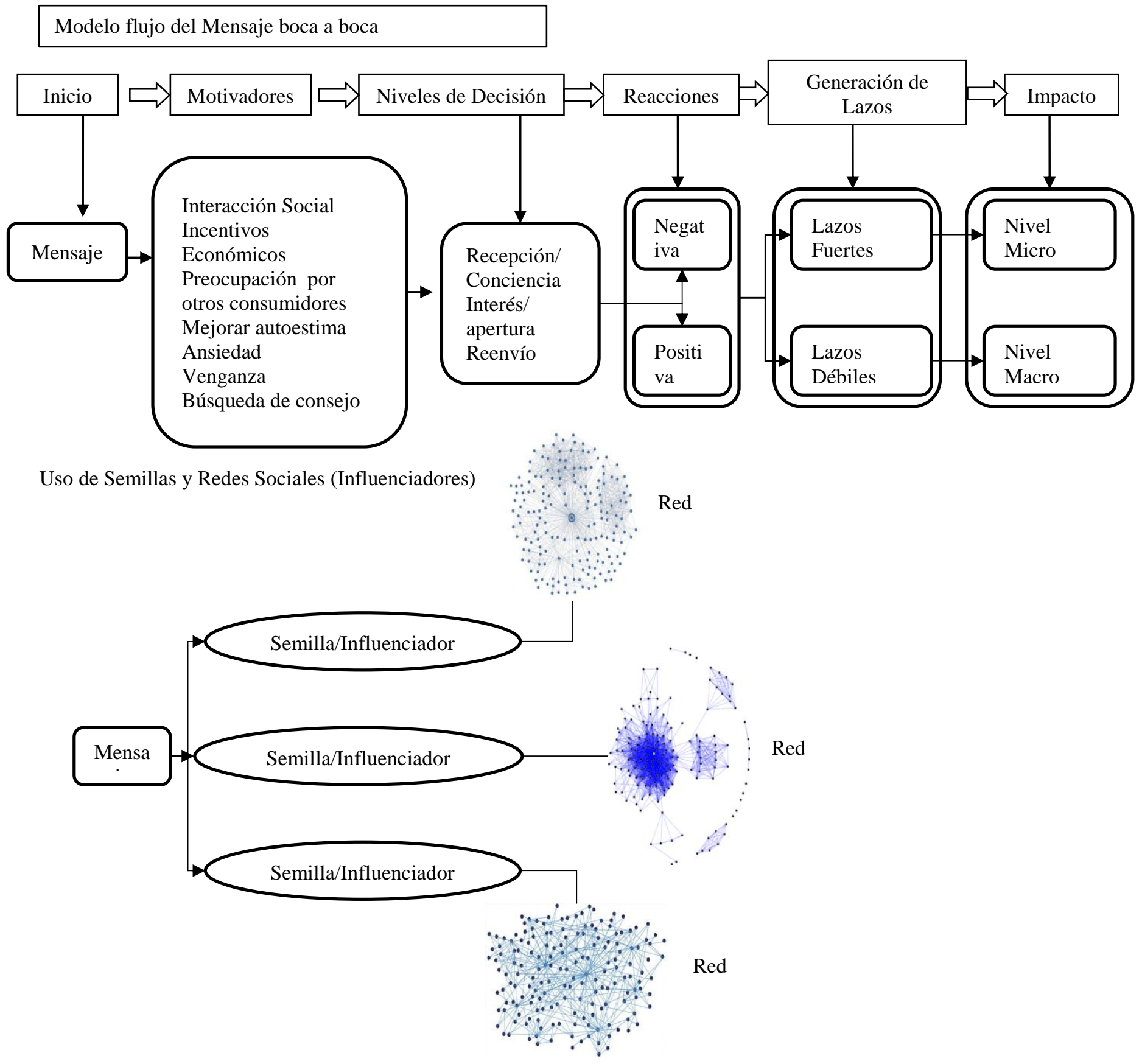

Fuente: elaboración propia

\section{DISCUSIÓN}

Aunque no existe una fórmula que garantice el éxito de una estrategia de Marketing viral, al crearse el contenido debe mover las emociones de las personas para generar interacción y difusión general de dicho contenido. Al igual, se debe considerar el canal de difusión, ya que juega un papel importante, máxime en esta época digital donde usar las redes sociales se posiciona como el canal número uno para el MV. Sin embargo, una alta difusión no es sinónimo de éxito o efecto positivo de la campaña o el contenido. Por lo tanto, el objetivo no es obtener difusión cueste lo que cueste. Una estrategia muy usada en la actualidad es el uso de las semillas, seleccionar personas influyentes en los diferentes medios para transmitir un mensaje o replicarlo en los diferentes grupos, dependiendo del mercado objetivo y sus características. 
La influencia que generan las condiciones del marco, en la primera etapa de decisión, ha sido poco tratada en la literatura anterior, pero existen evidencias de que dicho factor es importante al momento de definir si un contenido se tiene en cuenta o no. Por otro lado, los objetivos de interacción, presentan una influencia importante en la segunda etapa. Es normal que las personas se decidan a interactuar con el contenido si tienen motivaciones fuertes (por ejemplo, altruistas, egoístas o naturalistas). Por su parte, el contenido está presente en ambas etapas de la toma de decisiones. Este documento ofrece puntos de vista que pueden servir para futuras investigaciones.

Con la crisis desatada a nivel mundial por el COVID-19, el acelerado desarrollo de las tecnologías de la información y las comunicaciones (TIC) y el surgimiento de la Web 2.0 han generado un mayor involucramiento, participación e intercambio de información entre los clientes y las empresas. De hecho, el entorno digital ha propiciado el desarrollo de comunidades, en las cuales, la interacción y el intercambio de información son los elementos centrales, además, de ser útiles para generar y compartir conocimiento, son fuente de innovación y de valor para las empresas. Estas comunidades son el lugar perfecto para el desarrollo de estrategias de MV.

\section{CONCLUSION}

Esta investigación hace una revisión bibliográfica del tema "Marketing Viral". El resultado se planteó empleando la metáfora del árbol, para comprender, de una manera más visual, la evolución del concepto. La base teórica se refleja con las investigaciones de la "raíz". La estructura la reflejan los artículos del "tronco" y las subáreas se identificaron en los trabajos de las "ramas". Como resultado, se evidencia que las empresas pueden usar esta herramienta de difusión para generar posicionamiento y recordación, siempre y cuando el mensaje sea claro y difícil de desviar.

En lo que respecta a la producción académica en el área, se evidencia un aumento en el interés de la comunidad científica, esto reflejado en el aumento en el numero de publicaciones. Sin embargo, debido a la novedad del tema, las publicaciones aun no tienen un volumen importante, además, los registros obtenidos en la base de datos WoS se concentran en revistas de un impacto medio, y aun, sin un alto reconocimiento en el área de marketing.

Por otro lado, este trabajo da una visión muy general de la literatura existente en el tema Marketing Viral. Adicionalmente, se actualizaron las anteriores subáreas. Para esto, se expone un modelo que describe el proceso en la toma de decisiones en MV. Este modelo muestra que el proceso se realiza de una manera más compleja y dinámica que lo visto en la literatura previa. Además, permite estructurar de una manera más clara el área de investigación sobre el MV. Se realiza una clasificación en dos diferentes partes en la toma decisiones, donde se tratan el tema de la aceptación y la interacción con el contenido. Existen tres factores que ejercen influencia en estas etapas, como lo son, las condiciones del marco, el contenido y por último los objetivos de interacción.

Se presentaron limitaciones como el uso de una sola base de datos para la elección de artículos. De igual manera, el sesgo inevitable de los autores, al interpretar o analizar cada documento objeto de estudio. Nuevos estudios podrían identificar las diferentes subáreas a través de métodos cualitativos presentando casos de estudio para validar los hallazgos de este artículo. Para los profesionales e investigadores del marketing es de gran valor reconocer el marketing viral como una herramienta para la difusión, recordación y penetración de mercados de una manera masiva, así como también el uso de los canales actuales como el uso de las redes sociales y apuntar al marketing móvil.

\section{Declaración sobre conflictos de interés}

Los autores manifiestan que se encuentran vinculados como docente y estudiantes de la Universidad Católica Luis Amigó. En la ejecución del trabajo o la redacción del manuscrito no han incidido intereses o valores distintos a los que usualmente tiene la investigación.

\section{REFERENCIAS BIBLIOGRÁFICAS}

Akpinar, E. y Berger, J. (2017). Valuable Virality. JMR, Journal of Marketing Research, 54(2), 318-330. https://doi.org/10.1509/jmr.13.0350

Almeida, M. I. S., Costa, M., Coelho, R. L. F. y Scalco, P. R. (2016). "Engage and attract me, then I'll share you': an analysis of the impact of post category on viral marketing in a social networking site. Review of Business Management, 18(62), 545-569. https://doi.org/10.7819/rbgn.v18i62.2620

Aria, M. y Cuccurullo, C. (2017). Bibliometrix: 
MARKETING VIRAL: APLICACIÓN Y TENDENCIAS

An R-tool for comprehensive science mapping analysis._Journal of Informetrics, 11(4), 959-975. https://doi.org/10.1016/j.joi.2017.08.007 Aslay, C., Lu, W., Bonchi, F., Goyal, A. y Lakshmanan, L. V. S. (2015). Viral marketing meets social advertising: ad allocation with minimum regret. Proceedings of the VLDB Endowment International Conference on Very Large Data Bases, 8(7), 814-825. https://doi.org/10.14778/2752939.2752950

Bampo, M., Ewing, M. T., Mather, D. R., Stewart, D. y Wallace, M. (2008). The Effects of the Social Structure of Digital Networks on Viral Marketing Performance. Information Systems Research, 19(3), 273290. https://doi.org/10.1287/isre.1070.0152

Blichfeldt, B. S. y Smed, K. M. (2015). "Do it to Denmark": A case study on viral processes in marketing messages. Journal of Vacation Marketing, 21(3), 289-301. https://doi.org/10.1177/1356766715573652

Blondel, V. D., Guillaume, J-L., Lambiotte, R. y Lefebvre, E. (2008). Fast unfolding of communities in large networks. Journal of Statistical Mechanics,2008(10), P10008. https://doi.org/10.1088/1742$\underline{5468 / 2008 / 10 / \mathrm{P} 10008}$

Brown, J. J. y Reingen, P. H. (1987). Social Ties and Word-of-Mouth Referral Behavior. The Journal of Consumer Research, 14(3), 350. https://doi.org/10.1086/209118
Buitrago, S., Duque, P. y Robledo, S. (2020). Branding Corporativo: una revisión bibliográfica. ECONÓMICAS CUC, 41(1). https://doi.org/10.17981/econcuc.41.1.2020.Or g.1

Camarero, C. y San José, R. (2011). Social and attitudinal determinants of viral marketing dynamics. Computers in Human Behavior, 27(6), 2292-2300. https://doi.org/10.1016/j.chb.2011.07.008

Chae, I., Stephen, A. T., Bart, Y. y Yao, D. (2017). Spillover Effects in Seeded Wordof-Mouth Marketing Campaigns. Marketing Science, 36(1), 89-104. https://doi.org/10.1287/mksc.2016.1001

Chen, W., Wang, C. y Wang, Y. (2010). Scalable influence maximization for prevalent viral marketing in large-scale social networks. Proceedings of the 16th ACM SIGKDD International Conference on Knowledge Discovery and Data Mining - KDD '10, 1029.

https://doi.org/10.1145/1835804.1835934

De Bruyn, A. y Lilien, G. L. (2008). A multistage model of word-of-mouth influence through viral marketing. International Journal of Research in Marketing, 25(3), 151-163.

https://doi.org/10.1016/j.ijresmar.2008.03.00 $\underline{4}$

Dinh, T. N., Zhang, H., Nguyen, D. T. y Thai, M. T. (2014). Cost-Effective Viral Marketing for Time-Critical Campaigns in 
Pedro Duque-Hurtado, Adrián Toro-Cardona, Dahiana Ramírez-Carvajal y Martin Eugenio Carvajal-Henao

Large-Scale Social Networks. IEEE/ACM

Transactions on Networking, 22(6), 20012011.

https://doi.org/10.1109/TNET.2013.2290714

Dobele, A., Lindgreen, A., Beverland, M., Vanhamme, J. y van Wijk, R. (2007). Why pass on viral messages? Because they connect emotionally. Business Horizons, $50(4)$,

291-304.

https://doi.org/10.1016/j.bushor.2007.01.004

Dobele, A., Toleman, D. y Beverland, M. (2005). Controlled infection! Spreading the brand message through viral marketing. Business Horizons, 48(2), 143-149. https://doi.org/10.1016/j.bushor.2004.10.011

Duque, P. y Duque Oliva, J. (2020). Marketing digital y comercio electrónico: un análisis bibliométrico. In M. I. Redondo Ramírez, A. M. Barrera Rodríguez, y C. C. Duque Gómez (Eds.), Nuevos modelos de negocio (pp. 74-96). Centro de Investigaciones Facultad de Ciencias Económicas, Administrativas y Contables. http://hdl.handle.net/10901/18463

Duque, P. y Cervantes-Cervantes, L.-S. (2019). Responsabilidad Social Universitaria: una revisión sistemática y análisis bibliométrico. Estudios Gerenciales, 451464.

https://doi.org/10.18046/j.estger.2019.153.33 $\underline{89}$

Duque, P., Meza Aguirre, O. E., Zapata Lesmes, G. A. y Giraldo Castellanos, J. D. (2021).
Internacionalización de empresas latinas: evolución y tendencias. ECONÓMICAS CUC, 42(1). https://doi.org/10.17981/econcuc.42.1.2021.Or g.1

Duque, P., Samboni, V., Castro, M., Montoya, L. A. y Montoya, I. A. (2020). Neuromarketing: Its current status and research perspectives. Estudios

Gerenciales, 36(157). https://doi.org/10.18046/j.estger.2020.157.389 0

Ewing, M. T., Stewart, D. B., Mather, D. R. y Newton, J. D. (2014). How Contagious Is Your Viral Marketing Campaign?: A Mathematical Model for Assessing Campaign Performance. Journal of Advertising Research, 54(2), 205-216. https://doi.org/10.2501/JAR-54-2-205-216

Freeman, L. C. (1977). A Set of Measures of Centrality Based on Betweenness. Sociometry, $\quad 40(1), \quad 35$. https://doi.org/10.2307/3033543

Gao, C., Du, H., Wu, W. y Wang, H. (2020). Viral marketing of online game by DS decomposition in social networks. Theoretical Computer Science, 803, 10-21. https://doi.org/10.1016/j.tcs.2019.03.006

Godes, D. y Mayzlin, D. (2004). Using Online Conversations to Study Word-of-Mouth Communication._Marketing Science, 23(4), 545-560.

https://doi.org/10.1287/mksc.1040.0071 
Goyal, A., Bonchi, F. y Lakshmanan, L. V. S. (2010). Learning influence probabilities in social networks. Proceedings of the Third ACM International Conference on Web Search and Data Mining - WSDM '10, 241. https://doi.org/10.1145/1718487.1718518

Hennig-Thurau, T., Gwinner, K. P., Walsh, G. y Gremler, D. D. (2004). Electronic word-ofmouth via consumer-opinion platforms: What motivates consumers to articulate themselves on the Internet? Journal of Interactive Marketing, 18(1), 38-52. https://doi.org/10.1002/dir.10073

Hernández, D. S. V., Robledo, S., Pinilla, R., Méndez, N. D. D. y Tost, G. O. (2020). SAP Algorithm for Citation Analysis: An improvement to Tree of Science. Ingeniería E Investigación, 40(1), 4. https://dialnet.unirioja.es/servlet/articulo?codi go $=7345626$

Herr, P. M., Kardes, F. R. y Kim, J. (1991). Effects of Word-of-Mouth and ProductAttribute Information on Persuasion: An Accessibility-Diagnosticity Perspective. The Journal of Consumer Research, 17(4), 454. https://doi.org/10.1086/208570

Hinz, O., Skiera, B., Barrot, C. y Becker, J. U. (2011). Seeding Strategies for Viral Marketing: An Empirical Comparison. Journal of Marketing, 75(6), 55-71. https://doi.org/10.1509/jm.10.0088

Huang, H., Shen, H., Meng, Z., Chang, H. y He, H. (2019). Community-based influence maximization for viral marketing. Applied Intelligence, 49(6), 2137-2150. https://doi.org/10.1007/s10489-018-1387-8 Iyengar, R., Van den Bulte, C. y Valente, T. W. (2011). Opinion Leadership and Social Contagion in New Product Diffusion. Marketing Science, 30(2), 195-212. https://doi.org/10.1287/mksc.1100.0566 Jankowski, J., Zioło, M., Karczmarczyk, A. y Wątróbski, J. (2017). Towards Sustainability in Viral Marketing with User Engaging Supporting Campaigns. Sustainability: Science Practice and $\begin{array}{lll}\text { Policy, } & 10(2),\end{array}$ https://doi.org/10.3390/su10010015

Kaplan, A. M. y Haenlein, M. (2011). Two hearts in three-quarter time: How to waltz the social media/viral marketing dance. Business Horizons, 54(3), 253-263. https://doi.org/10.1016/j.bushor.2011.01.006 Kaplan, A. M. y Haenlein, M. (2012). The Britney Spears universe: Social media and viral marketing at its best. Business Horizons, $\quad$ 55(1), 27-31. https://doi.org/10.1016/j.bushor.2011.08.009 Kempe, D., Kleinberg, J. y Tardos, É. (2003). Maximizing the spread of influence through a social network. Proceedings of the Ninth ACM SIGKDD International Conference on Knowledge Discovery and Data Mining - KDD '03, 137. https://doi.org/10.1145/956750.956769

Koch, O. F. y Benlian, A. (2015). Promotional 
Pedro Duque-Hurtado, Adrián Toro-Cardona, Dahiana Ramírez-Carvajal y Martin Eugenio Carvajal-Henao

Tactics for Online Viral Marketing

Campaigns: How Scarcity and

Personalization Affect Seed Stage

Referrals. Journal of Interactive Marketing, 32 ,

37-52.

https://doi.org/10.1016/j.intmar.2015.09.005

Long, C. y Wong, R. C.W. (2014). Viral marketing for dedicated customers. Information Systems, 46, 1-23. https://doi.org/10.1016/j.is.2014.05.003

Marín López, J. C., Robledo, S. y DuqueMendez, N. (2017). Marketing Emprendedor: Una perspectiva cronológica utilizando Tree of Science. Revista Civilizar de Empresa Y Economía. https://revistas.usergioarboleda.edu.co/index.p hp/ceye/article/view/923

Mathieu, B., Sebastien, H. y Mathieu, J. (2009). Gephi: an open source software for exploring and manipulating networks. International AAAI Conference on Weblogs and Social Media. https://gephi.org/users/publications/

Nguyen, H. T., Thai, M. T. y Dinh, T. N. (2017). A Billion-Scale Approximation Algorithm for Maximizing Benefit in Viral Marketing. IEEE/ACM Transactions on Networking, 25(4), 2419-2429. https://doi.org/10.1109/TNET.2017.2691544

Ohri, A. (2012). $R$ for Business Analytics. Springer Science y Business Media. https://play.google.com/store/books/details?id $=\mathrm{D} 2 \mathrm{Su} 4 \mathrm{qomE} 4 \mathrm{sC}$
Palka, W., Pousttchi, K. y Wiedemann, D. G. (2009). Mobile Word-Of-Mouth - A Grounded Theory of Mobile Viral Marketing. Journal of Information Technology Impact, 24(2), 172-185. https://doi.org/10.1057/jit.2008.37

Pescher, C., Reichhart, P. y Spann, M. (2014). Consumer Decision-making Processes in Mobile Viral Marketing Campaigns. Journal of Interactive Marketing, 28(1), 43-54.

https://doi.org/10.1016/j.intmar.2013.08.001

Phelps, J. E., Lewis, R., Mobilio, L., Perry, D. y Raman, N. (2004). Viral Marketing or Electronic Word-of-Mouth Advertising: Examining Consumer Responses and Motivations to Pass Along Email. Journal of Advertising Research, 44(4), 333-348. https://doi.org/10.1017/S0021849904040371

Putri, N. K. y Ernawaty, E. (2019). Viral marketing content for Universal Health Coverage campaign in Indonesia. International Journal of Pharmaceutical and Healthcare Marketing, ahead-of$\operatorname{print}($ ahead-of-print), 2292. https://doi.org/10.1108/IJPHM-07-2017-0041

Reichstein, T. y Brusch, I. (2019). The decisionmaking process in viral marketing-A review and suggestions for further research. Psychology y Marketing, 36(11), 10621081.https://doi.org/10.1002/mar.21256

Robledo Giraldo, S., Osorio Zuluaga, G. A. y López Espinosa, C. (2014). Networking en 
MARKETING VIRAL: APLICACIÓN Y TENDENCIAS

pequeña empresa: una revisión bibliográfica utilizando la teoria de grafos. Revista Vínculos, 11(2), 6-16. https://doi.org/10.14483/2322939X.9664

Salazar, D. F. T., Álvarez, J. M. R., Garcés, J. J. H. y Duque, P. (2020). Riesgos en las Microfinanzas: Una revisión y análisis Bibliométrico. Interfaces, 3(2). http://www.unilibrecucuta.edu.co/ojs/index.ph $\mathrm{p} /$ ingenieria/article/view/484

Satrio, D., Priyanto, S. y Nugraha, A. (2020). Viral Marketing for Cultural Product: The Role of Emotion and Cultural Awareness to Influence Purchasing Intention. Montenegrin Journal of Economics, 16(2), 77-91. https://doi.org/10.14254/18005845/2020.16-2.6

Schulze, C., Schöler, L. y Skiera, B. (2014). Not All Fun and Games: Viral Marketing for Utilitarian Products. Journal of Marketing, $78(1)$, $1-19$. https://doi.org/10.1509/jm.11.0528

Sela, A., Goldenberg, D., Ben-Gal, I. y Shmueli, E. (2018). Active viral marketing: Incorporating continuous active seeding efforts into the diffusion model. Expert Systems with Applications, 107, 45-60. https://doi.org/10.1016/j.eswa.2018.04.016

Sharma, R. R. y Kaur, B. (2020). E-mail viral marketing: modeling the determinants of creation of "viral infection". MD Medical Newsmagazine, $\quad 58(1), \quad$ 112-128. https://doi.org/10.1108/MD-03-2017-0215

Tang, J., Tang, X. y Yuan, J. (2018). Profit Maximization for Viral Marketing in Online Social Networks: Algorithms and Analysis. IEEE Transactions on Knowledge and Data Engineering, 30(6), 1095-1108.

https://doi.org/10.1109/TKDE.2017.2787757 van der Lans, R., van Bruggen, G., Eliashberg, J. y Wierenga, B. (2010). A Viral Branching Model for Predicting the Spread of Electronic Word of Mouth. Marketing Science, $\quad 29(2), \quad 348-365$. https://doi.org/10.1287/mksc.1090.0520

Watts, D. J. y Dodds, P. S. (2007). Influentials, Networks, and Public Opinion Formation. The Journal of Consumer Research, 34(4), 441-458. https://doi.org/10.1086/518527

Zuluaga, M., Robledo, S., Osorio Zuluaga, G. A., Yathe, L., Gonzalez, D. y Taborda, G. (2016). Metabolómica y Pesticidas: Revisión sistemática de literatura usando teoría de grafos para el análisis de referencias. Nova, 14(25), 121. https://doi.org/10.22490/24629448.1735 